\title{
Correction to: Severity: a QoS-aware approach to cloud application elasticity
}

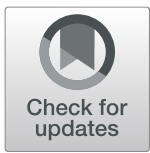

\author{
Andreas Tsagkaropoulos ${ }^{1,2^{*}}$, Yiannis Verginadis ${ }^{1,3}$, Nikos Papageorgiou ${ }^{1,2}$, Fotis Paraskevopoulos ${ }^{1,2}$, \\ Dimitris Apostolou ${ }^{1,4}$ and Gregoris Mentzas ${ }^{1,2}$
}

Correction to: J Cloud Comp 10, 45 (2021)
https://doi.org/10.1186/s13677-021-00255-5

Following publication of the original article [1], the authors identified an error. This error has been corrected to express more accurately the work of Arkian et al. [2]. This change should also make the last lines of the fourth paragraph of the Section on Rule-based and controltheoretic adaptation approaches more understandable. ${ }^{1}$

The erroneous and corrected text are published in this correction article. The original article has been updated.

Published online: 13 September 2021

References

1. Tsagkaropoulos A, Verginadis Y, Papageorgiou N, Paraskevopoulos F, Apostolou D, Mentzas G (2021) Severity: a QoS-aware approach to cloud application elasticity. J Cloud Comp 10(1):45. https://doi.org/10.1186/s13677021-00255-5

2. Arkian $\mathrm{H}$ et al (2021) Model-based Stream Processing Auto-scaling in GeoDistributed Environments. In: ICCCN 2021-30th International Conference on Computer Communications and Network

Incorrect

- When the performance is better than expected, a single processing instance is removed, while when it is worse, a single processing instance is removed.

\section{Correct:}

- When the performance is better than expected, multiple processing instances can be removed, while when it is worse, a single processing instance is added.

\section{Author details}

${ }^{1}$ Information Management Unit (IMU), Institute of Communication and Computer Systems, Athens, Greece. ${ }^{2}$ National Technical University of Athens (NTUA), Athens, Greece. ${ }^{3}$ Department of Business Administration, Athens University of Economics and Business, Athens, Greece. ${ }^{4}$ Department of Informatics, University of Piraeus, Piraeus, Greece.

1"Moreover, the scaling algorithms we define allow more than one instances to be added as necessary which reduces the number of reconfigurations."

The original article can be found online at https://doi.org/10.1186/s13677021-00255-5.

* Correspondence: atsagkaropoulos@mail.ntua.gr

${ }^{1}$ Information Management Unit (IMU), Institute of Communication and Computer Systems, Athens, Greece

${ }^{2}$ National Technical University of Athens (NTUA), Athens, Greece

Full list of author information is available at the end of the article

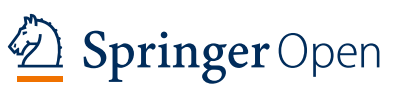

(c) The Author(s). 2021 Open Access This article is licensed under a Creative Commons Attribution 4.0 International License, which permits use, sharing, adaptation, distribution and reproduction in any medium or format, as long as you give appropriate credit to the original author(s) and the source, provide a link to the Creative Commons licence, and indicate if changes were made. The images or other third party material in this article are included in the article's Creative Commons licence, unless indicated otherwise in a credit line to the material. If material is not included in the article's Creative Commons licence and your intended use is not permitted by statutory regulation or exceeds the permitted use, you will need to obtain permission directly from the copyright holder. To view a copy of this licence, visit http://creativecommons.org/licenses/by/4.0/. 